\title{
Legitimidade espacial: uma discussão sobre mutação e permanência das estruturas espaciais urbanas
}

Norma LACERDA. Professora do Programa de Pós-graduação em Desenvolvimento Urbano (MDU) da Universidade Federal de Pernambuco (UFPE), Brasil.

LÚCIA LEITÃ̃ O. Professora do MDU da UFPE, Brasil.

Paulo Abílio de Queiroz. Arquiteto.

RESUMO | O objetivo deste ensaio é mostrar como certos processos de verticalização - particularmente naquelas áreas das cidades que passaram a ser suportes físicos de significações compartilhadas e, portanto, se transformaram em espaços simbólicos para os habitantes que as edificaram - provocam o desaparecimento de uma determinada organização espacial urbana, abalando de modo expressivo os princípios que regem as práticas sociais desses habitantes, inclusive aquelas relativas à apropriação (vivência) espacial. Assim sendo, trabalha-se com a hipótese de que esses processos de verticalização não são espacialmente legítimos. As referências teóricas vêm, notadamente, de Norberto Bobbio e Max Weber. Para desvendar, empiricamente, a existência dessa hipótese, elegeu-se o conjunto urbano de Casa Forte, localizado na cidade do Recife, Nordeste do Brasil.

PALAVRAS-CHAVE | Mercado imobiliário, estrutura urbana, morfologia urbana.

ABSTRACT | The aim of this essay is to demonstrate how specific processes of verticalization -particularly those in urban areas that become physical supports for shared meanings and are, as such, transformed into symbolic spaces for the inhabitants that built them - lead to the disappearance of a particular urban spatial organization, thereby clearly affecting the principles that govern the social practices of these inhabitants, including those related to spatial appropriation (experience). The hypothesis that is put forward is that these processes of verticalization are not spatially legitimate. The theoretical references are principally derived from Norberto Bobbio and Max Weber. Empirical evidence to support this hypothesis is provided from the Casa Forte neighbourhood in the city of Recife, North East Brazil.

KEY WORDS | Real state market, urban structure, urban morphology.

Recibido el 27 de febrero de 2009, aprobado el 9 de diciembre de 2009.

Correspondencia: E-mail: norma_lac@yahoo.com.br| luleitao@hotlink.com.br | pabilio@gmail.com 


\section{Introdução}

As ideias apresentadas neste texto resultam de um percurso reflexivo, iniciado com uma palestra proferida no I Fórum Nacional sobre Patrimônio Cultural, realizado em Belo Horizonte (Brasil), em 2004. Essa conferência teve como objetivo mostrar que os chamados projetos de reabilitação, em curso no Brasil - tendo como objeto de estudo o caso do bairro do Recife -, acompanhavam a tendência do chamado city marketing, tendo como consequência a aceleração da transformação de certas localidades, mediante intervenções imobiliárias especulativas, propriciadas pela implantação de grandes obras de renomados arquitetos.

Essas primeiras ideias - transformadas em um trabalho discutido no âmbito do $I X$ Seminario Internacional de la Red Iberoamericana de Investigadores en Globalización y Territorio, realizado em maio de 2005, em Bahia Blanca na Argentina - provocaram as seguintes questões postas em debate: $\mathrm{O}$ que vem acontecendo com o Bairro do Recife é um processo espacialmente legítimo? É legítimo transformar um espaço, um lugar praticado, como diria Michel de Certeau (2008), em um mero espaço de trânsito e de fluxos? Em um não-lugar, conforme definição de Marc Augé?

Esse debate, por sua vez, impulsionou a reflexão, com mais profundidade, sobre a legitimidade de intervenções que descaracterizam o patrimônio histórico e arquitetônico. Essas interrogações culminaram com a publicação de um artigo na Revista City \& Time (2005) ${ }^{1}$, com reflexões essencialmente teóricas. Até então, ainda não tinha sido possível harmonizar os esforços teóricos com um estudo empírico que nos ajudasse a compreender melhor a questão da legitimidade espacial, tendo como referência um tipo de intervenção urbanística em particular. ${ }^{2}$

Foi essa, pois, a oportunidade que nos ofereceu o X Seminário Internacional de la Red Iberoamericana de Investigadores en Globalización y Territorio, realizado em Querétaro, em maio de 2008. Mais uma vez, um debate suscitou novas inquietações. Desse modo, o texto que ora se apresenta aprofunda alguns conceitos-chave e apresenta o caminho metodológico percorrido até as conclusões a que foi possível chegar até o momento.

O trabalho tem como objetivo principal discutir como certos processos de verticalização, aqueles que se dão em áreas simbolicamente diferenciadas para a população, induzem ao desaparecimento de "lugares". Isso porque dificulta ou mesmo impossibilita determinadas "práticas espaciais" urbanas, ao alterar os princípios que regem as práticas sociais locais, inclusive aquelas relativas à apropriação (vivência) do ambiente construído.

A hipótese formulada parte do pressuposto de que muitos desses processos são espacialmente ilegítimos na medida em que redefinem -de forma impositiva- as práticas sociais até então vivenciadas por seus habitantes. São, portanto, intervenções urbanísticas que alteram radicalmente a tipologia edilícia principal, interferindo, por vezes brutalmente, na estrutura espacial desses ambientes e, consequentemente, nas práticas sociais que neles acontecem, tornado-as assim espacialmente ilegítimas.

É exatamente a ideia de legitimidade espacial que pretendemos explorar mais profundamente no contexto deste trabalho, associando-a a noção de memória coletiva e de identidade urbanística.

Para a investigação da hipótese, o caminho metodológico percorrido assinala três momentos. No primeiro, procurou-se investigar teoricamente se existe um nexo entre as seguintes categorias analíticas: permanências das estruturas espaciais urbanas

1 Revista do Centro de Estudos Avançados da Conservação Integrada (www.ceci-br. org).

2 No XIII Congresso de Sociologia (Recife, 2007) e no II Seminário Nacional Metrópole, Governo e Território (Rio de Janeiro, 2007), tivemos a oportunidade de mostrar as nossas primeiras reflexões, considerando os processos de verticalização de certas partes da cidade. 
(permanências estruturais) e a memória coletiva dos habitantes que as vivenciam. A evidência desse nexo impulsionou, por sua vez, a verificar se alterações nas referidas permanências não modificariam as tradições e os costumes desses habitantes, indo de encontro a um dos princípios do processo real de legitimação, definidos por Max Weber, conforme se verá adiante.

Num segundo momento, analisou-se a área de investigação empírica - um conjunto de localidades recifenses conhecido pela designação toponímica de Bairro de Casa Forte-, de modo a apreender o processo de construção da sua tipologia principal (do período colonial à década de 1970) e, em extensão, da memória coletiva, fundamento das práticas de vivenciar aquele conjunto. Considera-se que tempo e espaço, associados, definiram o modo como a identidade urbanística desse bairro se construía, se materializava, de geração em geração.

No derradeiro momento, investigou-se a hipótese considerando um conjunto de eventos sociais e políticos que tiveram o bairro de Cassa Forte como objeto de ação. Assim, verificou-se como a ameaça de destruição dessa tipologia impulsionou a formação de arranjos políticos para se opor ao processo de verticalização - a partir dos anos 1980 - è̀ consequente emergência de novas práticas sociais.

Esse caminho metodológico permitiu, pois, concluir que o desaparecimento de uma determinada estrutura tipológica, expressada na verticalização excessiva do bairro, impôs mudanças no modo de convivência social fortemente rejeitadas pela população local. Daí a ilegitimidade espacial do processo, conforme a hipótese formulada.

\section{Permanências estruturais, memória coletiva e legitimidade espacial}

A cidade é aqui compreendida como uma "unidade espacial". No entanto, como se sabe, ela não é homogênea. Segundo Lefebvre (2001), a produção do espaço não se dá de forma homogênea, mesmo quando se considera a tendência à homogeneização decorrente de práticas autoritárias. Ainda de acordo com o autor citado, a cidade é uma soma ou uma combinatória de elementos.

De fato, trata-se de uma unidade na diversidade, cuja compreensão necessita de uma análise simultaneamente particularizada e abrangente.

Essa unidade somente pode ser entendida por meio da dimensão temporal do território, portanto da sua historicidade. A metrópole é decorrente do acúmulo histórico de práticas urbanizadoras que modelaram um território com o uso de processos de estratificação (a arqueologia da ocupação urbana) e justaposição dos vários produtos da ação humana de domínio da natureza. É esse acúmulo que dá sentido humano e cultural à cidade.(Lacerda, Zancheti e Diniz, 2000).

Segundo Larochelle e Iamandi (1999, p.100):

Esta visão da história, parcialmente influenciada pelo impacto da 'nova história' (...) está relacionada à descoberta de processos cíclicos e oscilatórios e de fatos repetitivos. De acordo com esta nova dimensão histórica, aplicada a grandes áreas e longos períodos, pode-se perceber a estabilidade de repetições e se descobrir um componente estrutural. De acordo com Braudel a estrutura corresponde aos fatos que permanecem sem mudança por longos períodos de tempo ou que evoluem imperceptivelmente (as 'permanências estruturais'). 
Sendo assim, os diversos tempos sobre o território da cidade estão associados a diferentes processos históricos, que se sobrepõem e atuam simultaneamente (Secchi, 1998, pp.117-118). A questão da temporalidade está diretamente associada aos conceitos de mudança e permanência das estruturas ambientais urbanas. Nesses termos, o principal desafio das intervenções urbanísticas consiste em conciliar a transformação necessária do ambiente construído existente com a conservação de características essenciais herdadas que estão incorporadas em suas "permanências estruturais". A questão é se é "legítimo" um processo que interfere nessas "permanências, constituintes" da memória da cidade, elementos cruciais da identidade espacial de uma dada população.

Ora, a cidade, como bem afirma Duvignaud (1977, p. 50), é memória de si mesma. Se ela é memória de si mesma, é porque suas diversas estruturas espaciais, particularmente aquelas que resistiram a processos significativos de mudança no seu padrão de ocupação, passaram a ser detentoras de significados, a ser suportes físicos de significações compartilhadas. Passaram a ser, portanto, apoios simbólicos na constituição da identidade dos habitantes que, ao longo do tempo, as edificaram. Assim sendo, essas configurações espaciais, ao preservarem a memória coletiva das comunidades, respondem à necessidade de guardar -e de narrar- as suas próprias histórias, constituindo, assim, a memória que a cidade tem de si mesma, conforme foi mencionado antes.

Não sem razão, Dewitte (1999, p. 83), ao examinar a forma da cidade sob o ângulo particular da identidade, afirma que os lugares que, na cidade, materializam significações compartilhadas cumprem seu papel na medida em que "se por acaso eles (os habitantes) se esquecerem do que são, é suficiente, por assim dizer, retornar a este lugar para se recordar: ele é, na sua presença de pedra, a recordação sensível do que eles são."

Cada localidade da cidade, com sua respectiva comunidade, tem, pois, a necessidade de guardar e narrar a sua própria história. Essa necessidade será tão mais presente quanto maior for a capacidade de as estruturas urbanas revelarem essa história. Assim, o grau de transformação de cada uma delas será tão mais lento quanto mais tradicional for a comunidade. No caso das mais tradicionais, mudanças significativas na estrutura espacial implicariam transformações nos seus costumes, mais particularmente nas formas de "praticar o lugar". Mais ainda: poderiam pôr em jogo o sentimento de pertencimento próprio de quem habita um lugar. Nesse caso, o que está em questão é "o sentimento de" pertencer a um lugar - um espaço conhecido, diferenciado e delimitado - e a perda desse sentimento quando se vivencia a cidade em toda a sua extensão. Aliás, Lefebvre (1986, p. 339), em seu livro a "Produção do espaço", já salientava que o ser humano sabe que tem um espaço, mais ainda, que ele se encontra nesse espaço. "Fora dele, o estranho e o estrangeiro, o hostil." Frente às mudanças na tipologia principal, o sentimento de pertencimento suscita "legítimas" reações. Afinal, o passado deixaria de ser ponto de apoio para um futuro, necessariamente, desconhecido.

\section{A noção de legitimidade espacial}

Para um aprofundamento do conceito de legitimidade, é pertinente recorrer, em um primeiro momento, a Norberto Bobbio (2007, verbete Legitimidade) quando ele disserta sobre a legitimidade do Estado. De acordo com esse pensador, o termo "legitimidade" designa tanto uma situação quanto um valor de convivência social. $O$ valor é, por sua vez, o consenso livremente manifestado de uma comunidade de pessoas autônomas e conscientes. Mais ainda, a legitimidade, 
(É) uma unidade aberta, cuja concretização deve ser considerada possível num futuro indefinido, e a realidade concreta nada mais é do que um esboço desse futuro. Em cada manifestação histórica da Legitimidade, vislumbra-se a promessa, até agora sempre incompleta na sua manifestação, de uma sociedade justa, onde o consenso, que dela é a essência, possa se manifestar livremente sem a interferência do poder ou da manipulação e sem manifestações ideológicas (Bobbio, 1986, p. 678).

Isso significa que, tratando-se da legitimidade do Estado, essa existe enquanto potencial, projetando-se para o futuro a partir da realidade concreta atual e nunca é plenamente concretizada na história, a não ser como aspiração. Esse potencial, entendido como o consenso livremente manifestado, diz respeito evidentemente ao processo político.

Max Weber (1999, p.139), por sua vez, ao examinar as bases sociais e ideológicas dos sistemas de domínio, focaliza a aplicação ampla do princípio da legitimidade a sistemas de dominação. Assim, o sociólogo alemão, ${ }^{3}$ ao se debruçar sobre os diversos tipos de dominação, admite que "nem o costume ou a situação de interesse, nem os motivos puramente afetivos ou racionais referentes a valores de vinculação poderiam constituir fundamentos confiáveis de uma dominação. Normalmente, junta-se a esses fatores outro elemento: a crença de legitimidade".

Para Weber, existem três tipos de dominação ${ }^{4}$ considerados legítimos, que se fundamentam, por sua vez, em três tipos de motivaçóes: (i) as tradições e os costumes, provenientes da crença na santidade das tradições vigentes, ou seja, da força daquilo que dura há tempo, daquilo que sempre existiu e, por ter sempre existido, não conhece razões para ser alterado (dominação tradicional); (ii) os procedimentos legais, derivados da crença na legitimidade das ordens estatuídas, isto é, na racionalidade do comportamento conforme a lei (dominação legal), e (iii) o carisma, oriundo da crença baseada na veneração extracotidiana da santidade, do poder heróico ou do caráter exemplar de uma pessoa, em suma, dos dotes admiráveis de um determinado indivíduo (dominação carismática). Weber não excluía a possibilidade de relação entre esses tipos de dominação, admitindo ser difícil estabelecer onde começa um e termina o outro (Weber, 1999, p. 141).

Ora, se um dos tipos de dominação legítima é fundamentado na crença nas tradições e nos costumes, o consenso livremente manifestado - nos termos colocados por Bobbio - pode referir-se, também, ao processo espacial. Isso significa que esse consenso pode circunscrever-se territorialmente, existindo também como potencial que dificilmente se manifesta sem a interferência do poder ou da manipulação e sem manifestações ideológicas.

Quando se trata dos espaços da cidade, carregados de significados compartilhados por seus habitantes e, ao mesmo tempo, objetos de interesse do setor imobiliário, é importante considerar que a cada um desses espaços, em geral, corresponde uma coletividade territorial, "onde a coesão e a comunidade de habitantes, não sobre todos os planos, mas ao menos sobre aqueles dos interesses territoriais, é forte o suficiente para criar um consenso que se impõe a todos" (Ledrut, 1968, p. 18), evidentemente à exceção do referido setor. Isso significa a existência de consensos localizados e conflitantes: de um lado, os interesses territoriais da comunidade e, de outro, os do setor imobiliário. Daí, a necessidade de intervenção do Estado, ao estabelecer procedimentos legais.

3 Ao examinar as bases sociais e ideológicas dos sistemas de domínio, esse sociólogo focaliza um dos temas importantes sobre o assunto, ou seja, a aplicação ampla do princípio da legitimidade a sistemas de dominação.

4 Para Weber (1999, p. 139), "dominação" significa a "probabilidade de encontrar a obediência para ordens específicas (ou todas) dentro de determinado grupo de pessoas." partes da cidade. 
No entanto, deve-se admitir que intervenções urbanas, mesmo fundamentadas em procedimentos legais (dominação legal), quando desconhecem as tradições e os costumes manifestos no ambiente construído, vão de encontro a um dos princípios do processo real de legitimação (dominação tradicional), desorganizando os fundamentos das práticas sociais. Afinal, como afirmam Remy \& Voye (1992 p. 25):

Existe um laço biunívoco entre a estrutura espacial e a estrutura social ao ponto que - como demonstra Lévi-Strauss com o exemplo dos Bororos -, caso se desmanche a estrutura espacial, se desorganiza no mesmo golpe os princípios de base do agir coletivo. O espaço é a formalização maior da cultura do grupo e de suas regras de funcionamento social.

Haveria, portanto, uma "legitimidade espacial" cujos fatores determinantes se encontram na própria dimensão espacial. Esses fatores estariam vinculados tanto ao reconhecimento das "permanências estruturais", que, por sua vez, definem as estruturas urbanas mais resistentes à transformação e que mais contribuem para a consolidação da memória coletiva (Larochelle e Iamandi, 1999, p. 100), quanto ao respeito pelo espaço na definição que lhe dá Michel de Certeau, isto é, aos "lugares praticados", espaços onde a vida de todos e de cada um não se dissocia do ambiente onde vivem. Portanto, o reconhecimento de uma "legitimidade espacial" revelaria a pertinência das ações desenvolvidas no território, quer em sua expressão política, quer em sua manifestação socioespacial.

Nesse sentido, as ações que vão de encontro às "permanências estruturais" poderiam causar uma ruptura ou descontinuidade da identidade espacial. Sendo assim, ações que se queiram legítimas em relação ao espaço urbano pressupõem um processo que reconheça esse laço biunívoco entre a estrutura espacial e a prática social, cujo agir se realiza mediante o respaldo do valor da convivência social. É o que se analisará a seguir mediante o estudo do conjunto urbano de Casa Forte.

\section{Casa Forte: espaço e significações compartilhadas ${ }^{5}$}

"Agora eu estou entrando no Recife pitoresco, sentimental histórico de Apipucos e do Monteiro, do Poço da Panela, da Casa Forte e do Caldereiro, onde há poças de tempo, estagnadas sob as mangueiras, da Santana de Fora e da Santana de Dentro, das muitas olarias rasas, agachadas do vento." (João Cabral de Melo Neto)

Agora, o "Recife pitoresco, sentimental, histórico..." O urbanista, assim como outros profissionais, deve, muitas vezes, retrair-se diante do poeta. Nada falta no texto anotado como epígrafe, para a descrição do conjunto urbano ora estudado: as "poças de tempo estagnadas", as mangueiras, as antigas olarias, até a citação minuciosa dos bairros reagrupados, para os fins deste texto, sob o nome de Casa Forte: Parnamirim, Santana, Casa Forte, Poço da Panela, Monteiro e Apipucos. Nesses leves traços da pluma do poeta encontramse as representações sociais construídas ao longo da história dessas localidades.

O rio Capibaribe, com suas várzeas, constitui um condicionante natural do processo de implantação da cidade do Recife. Explica-se, assim, porque, com muita freqüência, canaviais e engenhos foram surgindo ao longo das margens do curso inferior desse rio,

5 Este item fundamenta-se em grande parte em Lacerda, N. La production sociale des intérêts fonciers et immobiliers: les cas de Recife (Brésil). Paris, Sorbonne Nouvelle - Paris III, 1993 (tese de doutorado). 
desde a primeira metade do século XVII. Dentre eles, o de Casa Forte, o do Monteiro e o de Apipucos. Tais engenhos deram lugar a pequenas aglomerações ou povoações que, ainda hoje, guardam seus nomes de origem. Com o final do século XVIII, o cultivo da cana-de-açúcar começou a declinar e as aglomerações de Casa Forte, Apipucos e Monteiro principiaram a se estender, acompanhando a subdivisão de seus "sítios", dando origem a localidades como Chacon, Poço da Panela e Santana.

O deslocamento das habitações nobres do centro da cidade para os bairros periféricos deu uma nova significação ao conjunto urbano denominado Casa Forte, que se tornou um lugar elegante, acolhedor da burguesia rica e refinada. Os anúncios nos jornais locais indicavam a valorização das casas dentro de chácaras, ou "sítios", e de espaçosos quintais, onde havia pomares e até mesmo pastagens.

Através da história, de geração em geração, a identidade urbanística desse bairro se construía, se materializava numa mistura de realidade e ficção, em que simultaneamente transitavam a história e o desejo de permanência. O bairro conhecerá transformações; não obstante, sua essência estava lá desde o inicio: um bairro tranquilo, verde, próximo da natureza. E, nesse caso, "a história não é mais nostalgia, mas ponto de apoio. O futuro não é desconhecido, mas construtível (...). Nenhuma necessidade de procurar uma essência, uma natureza lá onde é a história que desempenha plenamente este papel" (Ostrowetsky, 1983, p.165).

As mutações fundiárias nos bairros apareceram notadamente no período de 1940 a 1960, quando vários "sítios" foram loteados. Nos anos 1960, o ritmo de parcelamento de antigos "sítios" diminuiu. A quase totalidade dos grandes patrimônios fundiários de Casa Forte encontrava-se, nessa época, loteada. A partir de então, assistiu-se a um processo de desmembramento, assinalando a divisão de terras em dois ou três lotes para a venda ou para a repartição entre herdeiros.

Esse processo permitiu que, ao lado da burguesia refinada, surgisse uma classe média formada por intelectuais, artistas e funcionários públicos, atraída não apenas pela singularidade desse conjunto urbano, mas também pela presença nesse bairro da Fundação Joaquim Nabuco (Fundaj) e pela proximidade com a Superintendência de Desenvolvimento do Nordeste (Sudene) e as duas Universidades Federais localizadas na cidade. ${ }^{6}$ Esses segmentos sociais conviviam com outros de menor renda que foram ocupando espaços nessa área, sobretudo às margens do rio Capibaribe. A estrutura peculiar espacial do bairro, até então essencialmente horizontal, explicitava as relações sociais, não apenas entre os diferentes grupos, mas também as relações interpessoais, como se pode constatar pelo depoimento, por exemplo, do dramaturgo Ariano Suassuna, morador do bairro onde também se localizava a favela a Vila do Chacon. Diz Suassuna: "Eu imediatamente estabeleci uma relação paternalista com seus habitantes. Eu me transformei em médico, policial e pai. A favela quase desapareceu, mas eles são loucos por mim. Alguns se consideram o meu anjo da guarda."

A visão do representante dos moradores da favela do Poço da Panela confirma esse depoimento.

Quando havia um problema na comunidade, sempre tínhamos o apoio da classe média. Há um barão do açúcar. Ele queria comprar um terreno para que se casa ficasse longe da favela para evitar barulhos. Ele não conseguiu. Às vezes, ele vem falar com o povo. O seu guarda-costa vem junto (entrevistas, 1990). 
Esse tipo de relação social entre a classe média e os segmentos sociais de baixa renda, mediada pela estrutura espacial, revela, do ponto de vista político, um daqueles tipos de dominação identificados por Weber (1999, p.148), cuja "legitimidade repousa na crença de ordens e poderes senhoriais tradicionais ('existentes desde sempre'). Determina-se o senhor (ou os vários senhores) em virtude de regras tradicionais" (dominação tradicional), tanto quanto no sentido da vivência de um espaço que se legitima pelas práticas sociais que esse espaço abriga.

Além disso, os bares, as padarias e a Praça de Casa Forte, esta última um espaço acolhedor, projeto feliz do arquiteto Roberto Burle Max, facilitavam os encontros dos habitantes, como se fossem possuidores de "chaves de contato". Eram espaços que lhes ofereciam oportunidades de confrontar sua identidade e, assim, fazer parte do simbolismo desse conjunto, simbolismo que seria, em um futuro próximo, ameaçado, mediante a iminente destruição da sua tipologia principal.

O que se veria daí para frente, seria um conflito entre o consenso livremente manifestado pelos habitantes do bairro - consenso construído a partir das tradições e costumes de vivenciar aquele espaço- e os interesses de um determinado setor empresarial, o setor imobiliário. Esse conflito estende-se ao âmbito dos poderes executivos e legislativos locais, como se verá a seguir.

\section{Casa Forte: destruição da tipologia principal e reação dos moradores}

No fim dos anos 1970, começava outro processo de mutação fundiária. Os loteamentos e desmembramentos praticamente desapareceram, dando lugar a um processo inverso. Era necessário remembrar os terrenos para que suportassem as operações imobiliárias. Essas operações resultaram em edifícios com arquitetura de linhas puras, vidros que permitiram a integração com a paisagem verde e fachadas em material nobre, imprimindo um ar de modernidade aos bairros. Modernidade, no entanto, contrariada pelos nomes dos edifícios (Porta d’Água, Baraúna, Canavial, Bangüê, Senzala, Casa Grande...), que enviava sempre ao passado, à vida nos antigos engenhos que antecederam a face urbana atual de Casa Forte - o que aponta para a necessidade de permanência de que se falou antes.

$\mathrm{O}$ apelo ao passado e as alusões à natureza tendem a preservar - contra os assaltos da modernidade-as marcas identitárias (Leitão, 2007) desses bairros. Por marcas identitárias deve-se compreender um conjunto de referências de natureza subjetiva que faz com que os moradores dessas áreas se reconheçam como parte dos próprios bairros, vivenciando assim o sentimento de "pertencimento espacial" (Leitão, 2007), como se, ainda que metaforicamente, sujeito e espaço fossem uma só unidade. Mais uma vez, o poeta nos ajuda a compreender melhor essa relação de pertencimento especial de que se fala aqui, quando assim se expressa: "Eu sou mameluco, / sou de Casa Forte / Sou Pernambuco / sou o Leão do Norte" . O tempo continuava, portanto, reforçando a construção de uma identidade espacial para uma burguesia urbana, cujas práticas sociais visavam recriar o passado e, em certa medida, negar o urbano, valorizando as aparências agrárias do bairro.

Tratava-se de uma verticalização ainda incipiente naquela época. As edificações não ultrapassavam 16 andares. No entanto, na década de 1980, com o intenso processo de adensamento construtivo nos bairros vizinhos, Casa Forte transformou-se em local privilegiado de expansão dos investimentos imobiliários. Até o início dessa década, seu espaço era considerado suburbano, com baixo coeficiente de ocupação. 
A partir do início da segunda metade dos anos 1980, precipitaram-se os acontecimentos que ocasionaram alterações no processo de ocupação do bairro. Para isso, contribuiu o episódio que consistiu no movimento popular de protesto contra a construção de um edifício de 17 andares nos limites do Poço da Panela, área de preservação rigorosa. O resultado foi a criação do movimento Amigos de Casa Forte. Tratava-se de "uma causa sagrada”, de preservação dos melhores valores da área: histórico, ecológico e social. O imóvel em questão passava a ser visto como símbolo construído em homenagem à glória da promoção imobiliária, um símbolo para os moradores da área, da profanação de um espaço quase sagrado.

A permanência da sua "tipologia principal" estava então seriamente em perigo. Os arranjos políticos começaram a se conformar. De um lado, uma comunidade constituída por uma classe média numerosa, consciente e organizada, e, de outro, os promotores imobiliários e os proprietários dos terrenos. Desde o início, os Amigos de Casa Forte contaram com o apoio do mundo intelectual, valorizado por personalidades de destaque e de associações vinculadas à proteção ambiental. Mas era necessário contar também com o apoio dos segmentos pobres da população, para quem a verticalização representava um perigo em razão da valorização fundiária.

Durante o processo de sensibilização da população, a Igreja Católica não esteve ausente. Próxima da classe média, ela imediatamente aderiu ao movimento. Os membros de certos partidos políticos de esquerda também abraçaram a causa. As associações profissionais, Instituto de Arquitetos do Brasil (IAB) e Ordem dos Advogados do Brasil (OAB), foram chamadas para participar dos debates. A Fundaj elaborou estudos sobre a história e a arquitetura do bairro. Manifestações públicas foram organizadas, a exemplo da denominada 'marcha ecológica'. Uma petição foi encaminhada à Prefeitura com 2.500 assinaturas, contendo, inclusive, o nome de Gilberto Freyre, morador do bairro, um nome especialmente prestigiado não apenas na cidade, mas também uma personalidade celebrada nos níveis nacional e internacional, denunciando junto às autoridades competentes a construção do imóvel de 17 andares. Por outro lado, os proprietários fundiários também se mobilizaram, recolhendo cerca de 700 assinaturas contra as possíveis mudanças nas normas urbanísticas vigentes.

Em abril de 1986, o movimento Amigos de Casa Forte solicitou uma revisão da Lei de uso e ocupação do solo (Luos). A demanda foi encaminhada à Empresa de Urbanização do Recife (URB) para a elaboração da proposta técnica, cujo conteúdo integrava largamente as reivindicações dos habitantes de Casa Forte. Paralelamente a essa iniciativa, outra proposição era elaborada fora da URB, propondo a continuação do processo de verticalização. Em fevereiro de 1987, esta última proposta foi aprovada pela Comissão Especial de Acompanhamento do Plano de Uso e Ocupação do Solo e, posteriormente, pelo Conselho de Desenvolvimento Urbano (CDU).

Diante de tal situação, o prefeito não encontrava posições políticas conciliatórias, nada que pudesse assemelhar-se a um consenso. Assim fazendo, evidenciava a incapacidade do Poder Executivo de exercer sua função de instância mediadora de interesses conflitantes. Para atenuar a sua imagem diante da comunidade, o Executivo enviou também ao Legislativo a proposta da Empresa de Urbanização do Recife (URB), fazendo menção de que se tratava de uma proposta mais adequada ao bairro no que concernia à preservação de áreas verdes e de sítios históricos.

No que se refere ao Legislativo, durante dois anos o setor imobiliário conseguiu obstaculizar as votações. Finalmente, imediatamente após a mudança dos membros da Câma- 
ra, os Amigos de Casa Forte relançaram a mobilização, não havendo tempo para o setor imobiliário organizar as suas alianças. Durante a reunião plenária de março de 1989, a Câmara estabeleceu novos parâmetros urbanísticos para a área. O tranquilo e fascinante bairro de Casa Forte passou a ter seu processo evolutivo protegido em relação ao risco das distorções comumente engendradas por poderosos investimentos imobiliários. Essa ocorrência veio a se tornar mais uma das suas singularidades. Afinal, tratava-se da vitória de uma comunidade em particular em relação aos empreendedores imobiliários.

Restava saber até quando o processo de verticalização não comprometeria "as permanências” do lugar. Retomando Ledrut (1968, p. 18), provavelmente ele definiria esse lugar de acordo com os termos anteriormente ressaltados, ou seja, como uma coletividade onde a coesão de seus habitantes, fundamentada nos interesses territoriais, é capaz de criar um consenso que se impõe a todos que integram essa coletividade.

No entanto, seis anos após a regulamentação dos novos parâmetros urbanísticos, Casa Forte abriu as portas ao setor imobiliário, com a aprovação de uma nova lei mais flexível, o que permitiu um processo de adensamento construtivo e de verticalização sem precedentes (ver Gráfico 1). A comunidade, apoiada na consciência da importância da memória coletiva que o espaço edificado propicia para uma comunidade, reagiria novamente, consciente de que "o desaparecimento de uma determinada ordem urbana implica a emergência de uma outra ordem" (Choay, 1965, p.14), uma nova ordem urbana que colocaria em jogo as suas tradições e os seus costumes, um dos tipos de motivação que, como foi visto, impulsiona ações consideradas como "espacialmente legítimas".

GRAFICO 1 | Área construída por bairro até 1982 e de 1983 a 2000

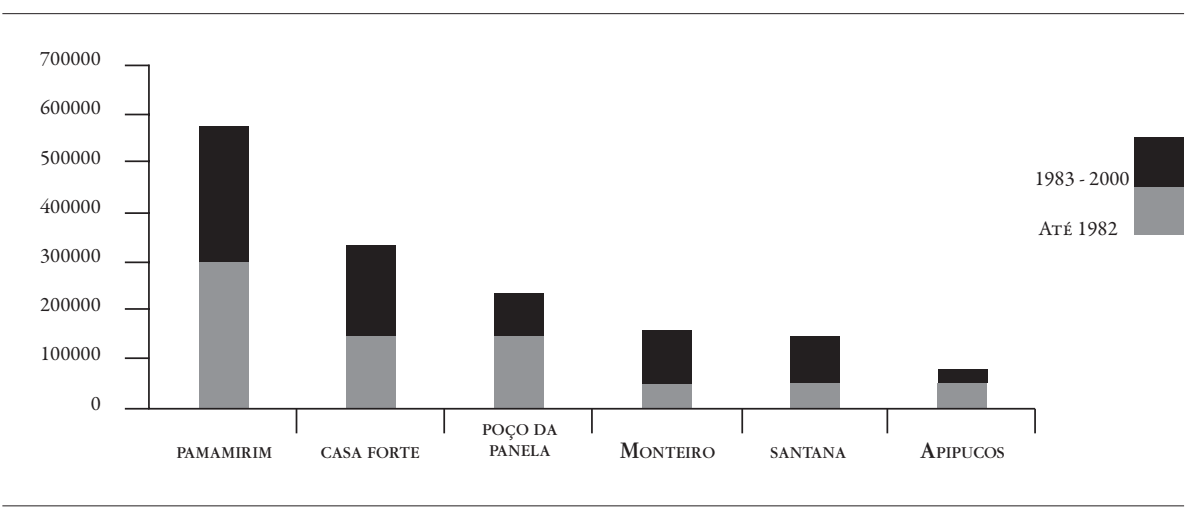

FONTE PREFEITURA DO RECIFE/SECRETARIA DE FINANÇAS, CADASTRO IMOBILIÁRIO, 2000.

Assim, o conjunto urbano de Casa Forte passou - à revelia do consenso livremente manifestado por seus habitantes, pessoas autônomas e conscientes nos termos utilizados por Bobbio - a conhecer outro tipo de dominação no que se refere ao processo de produção do seu espaço. Tratava-se, então, de uma legitimidade essencialmente baseada na ordem instituída, mas especificamente nos novos parâmetros estabelecidos para a sua ocupação espacial (dominação legal). O consumo do espaço por seus habitantes, nos moldes anteriormente descritos, foi paulatinamente sendo substituído pelo consumo do espaço por um determinado grupo empresarial e por integrantes de segmentos sociais mais preocupados em consumir individualmente as qualidades desse espaço do que em vivenciá-las coletivamente. 
Em 2001, impulsionados por uma gestão municipal comprometida, à época, com os anseios da comunidade, os Amigos de Casa Forte recomeçam, mais uma vez, a solicitar restrições quanto às novas formas de ocupação, tendo como fundamento as permanências da singularidade da área, apesar dos percalços então existentes.

Desde a campanha eleitoral, a gestão municipal então no poder assumiu o compromisso de revisar os polígonos congelados nos bairros das Graças e Poço da Panela. A Secretaria de Planejamento e Urbanismo (Seplam) elaborou então um estudo que alargou esse polígono e nele incluiu doze bairros, dentre os quais os seis que conformam o conjunto urbano conhecido como Casa Forte. O estudo demonstrava a aceleração do processo de transformação da área, tanto em termos de aumento da área construída como de alteração do padrão de ocupação -que passaria a ser predominantemente vertical-sobrecarregando, inclusive, a infra-estrutura.

A apresentação desse estudo em reunião do CDU resultou na indicação de ampliação dos perímetros de "congelamento" para toda a extensão dos doze bairros por um prazo de sessenta dias, tempo necessário para a elaboração de uma proposta de revisão da legislação urbanística em vigor.

A decisão de congelamento foi referendada pelo Prefeito mediante um decreto municipal que suspendeu as análises de projetos nesses sessenta dias. O impacto na mídia e nos setores ligados à construção civil foi enorme. Várias manifestações de protesto foram veiculadas, exercendo grande pressão sobre a opinião pública. Em poucos dias, uma reunião extraordinária do CDU referendava as deliberações anteriores. Os atores sociais estavam rapidamente se adaptando a um Conselho com poder decisório de fato.

Após diagnósticos, análises e simulações, a minuta de lei que indicava alterações nas condições de uso e ocupação do solo para a área dos doze bairros foi apresentada ao CDU. Essa proposta não incorporava as contribuições dos conselheiros representantes do setor imobiliário que acompanharam os trabalhos técnicos.

Nesse contexto, os interesses setoriais ficaram explícitos. Grosso modo, dois grupos se delineavam: aqueles que defendiam a agenda dos promotores imobiliários e aqueles favoráveis às restrições no processo de ocupação dos doze bairros. Diante das divergências, o Conselho foi levado a buscar uma solução negociada e, assim, foi criada uma comissão composta por representantes desses dois grupos, com poderes para discutir possíveis alterações na proposta inicial. O resultado foi um Anteprojeto de Lei com poucas alterações quando comparado com a proposta técnica inicial. Entretanto, a legitimidade política dessa segunda "versão" estava enormemente ampliada, isso porque os representantes do setor imobiliário não tiveram como se omitir do debate (pois ele já era público) e se viram diante da inevitável legitimação da proposta, que agora era considerada a proposta do CDU, assinada por todos os conselheiros da Comissão.

O fato de o projeto ter sido enviado à Câmara assinado pelos conselheiros do CDU, inclusive por aqueles ligados ao setor imobiliário, pesou para a sua aprovação por unanimidade, fato inédito em se tratando de lei de uso e ocupação do solo. A estratégia política de condução do processo foi capaz de construir um consenso mediante a interferência do poder municipal, cujo principal respaldo era a permanência daquelas características que haviam sobrevivido ao processo de verticalização.

Mas, já não era tarde? Quando ocorreu o processo de congelamento dos doze bairros, 42 prédios haviam sido aprovados, embora ainda não tivessem sido construídos. Todos foram edificados e apresentavam em comum uma excessiva verticalização. Os gabaritos dessas novas edificações comportam de trinta a quarenta e dois pavimentos. 
Esse processo significou também uma maior elitização espacial. Os dados do Quadro 1, apresentado a seguir, confirmam que no conjunto urbano de Casa Forte ocorreu um incremento da renda média do chefe dos domicílios em praticamente todos os bairros, à exceção de Apipucos, por conta da ampliação das áreas pobres que nele se localizam. A elitização espacial, por sua vez, vem atraindo o "terciário nobre", reforçando ainda mais uma centralidade voltada para a elite, não só local, mas metropolitana. Assim, paulatinamente, parte importante desse conjunto vem se transformando em espaço de trânsito e de fluxo.

Nessa nova Casa Forte, as padarias, os bares, a Praça de Casa Forte, assim como outros ambientes de convívio, vem se perdendo enquanto lugares de encontro. A solidariedade entre o segmento daquela classe média e a população de mais baixa renda que ainda mora no bairro se desvaneceu. Afinal, muitas famílias venderam as suas casas às incorporadoras, permanecendo em Casa Forte mediante troca do terreno por área

QUADRo 1 | Conjunto urbano de Casa Forte - Recife Renda média do chefe dos domicílios |1991-2000

\begin{tabular}{l|l|l|l|l}
\hline \multirow{2}{*}{ BAIRROS } & \multirow{2}{*}{1991} & \multirow{2}{*}{2000} & Incremeto & \\
\cline { 4 - 5 } & & & V.abs. & $\%$ \\
\hline PAMAMIRIM & $2,782.79$ & $3,546.99$ & 764.20 & 27.46 \\
CASA FORTE & $2,925.03$ & $3,970.00$ & $1,044.97$ & 35.73 \\
POÇO DA PANELA & $2,475.68$ & $2,848.08$ & 372.40 & 15.04 \\
MONTEIRO & $2,422.91$ & $3,431.14$ & $1,008.23$ & 41.61 \\
SANTANA & $1,249.30$ & $1,735.65$ & 486.35 & 38.93 \\
APIPUCOS & 582.99 & 504.39 & $(78.60)$ & $(13.48)$ \\
\hline
\end{tabular}

FONTE ATLAS DE DESENVOLVIMENTO HUMANo Do RECIFE, 2005. DADOS DOS CENSOS DEMOGRÁFICOS DE 1991 E 2000.

FIgURA 1 | Conjunto urbano de Casa Forte - Recife

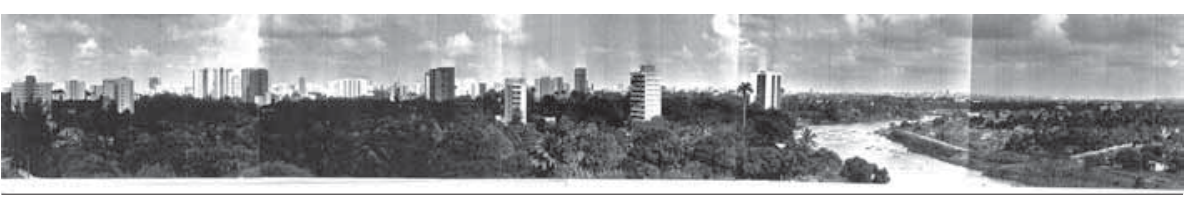

FOTO FLÁVIA LACERDA, 1991.

FIGURA 2 | Conjunto urbano de Casa Forte - Recife

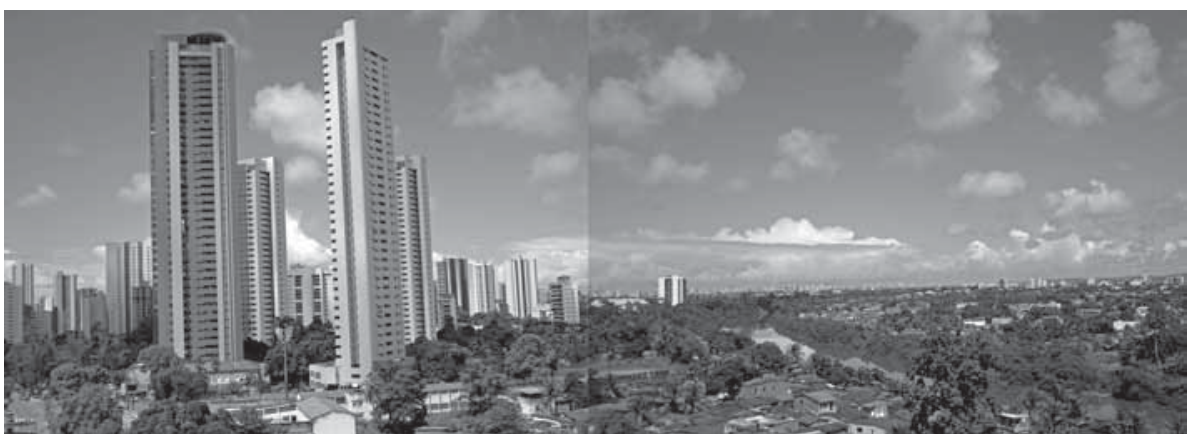

FOTO NORMA LACERDA, 2007. 
construída, ou foram habitar em outro bairro do Recife. A paisagem mudou, conforme se vê nas Figuras 1 e 2, e, com ela, a forma de vivenciar o bairro. A Figura 1, de 1991, embora assinale certa verticalização na estrutura espacial de Casa Forte, mostra a exuberância da vegetação, essencialmente decorrente da arborização dos quintais. A Figura 2, de 2007, retirada praticamente do mesmo ângulo, evidencia a excessiva verticalização e, com ela, a redução expressiva da cobertura vegetal.

\section{Conclusões}

Foi exatamente a percepção da interdependência, em determinadas situações, entre as tradições/costumes, representados pela tipologia principal, e o agir coletivo que despertaram as inquietações sobre a possível relação entre a tipologia principal, a memória coletiva e a legitimidade espacial, inquietações que nos conduziram ao questionamento sobre a legitimidade de intervenções que produzem mudanças importantes em estruturas espaciais consolidadas, mesmo sendo elas respaldadas em procedimentos legais. Em outras palavras, intervenções urbanísticas que desconsideram o que se ponderou como sendo espaços de significações compartilhadas por toda uma comunidade, lugares praticados, como diria Michel de Certeau.

Mais ainda, essa percepção levou a considerar que o desaparecimento de uma determinada estrutura urbana, ou seja, a destruição das permanências estruturais urbanas teria como desdobramento mudanças em termos dos valores de convivência social, impulsionando a comunidade a agir coletivamente. Nesse caso, legitimamente, mediante arranjos políticos que visam à sua conservação.

Todo esse processo nos leva a situar o simbólico, e seus laços com a territorialidade, no centro das reflexões ora apresentadas. Como admitem Remy e Voye (1992, p.166), o espaço revelou-se como mediador dos fenômenos registrados, "uma modalidade de composição entre as atividades e os grupos. Nessas concretizações, o espaço é, ao mesmo tempo, indutor e induzido, como mostram, por exemplo, a morfologia, o habitat e os aspectos socioeconômicos e socioafetivos da vida social."

Existe, pois, uma relação não apenas entre estrutura espacial e memória coletiva, mas também entre estrutura espacial e legitimidade das intervenções nessa estrutura, o que nos permite falar em processos espacialmente legitimos ou ilegitimos.

Compreender esses processos é um desafio para o planejamento urbano neste século que se inicia, uma vez que a importância da subjetivação na constituição da cidade ainda não foi adequadamente explorada, quiçá compreendida, por muitos daqueles que intervêm cotidianamente no espaço humano.

Provavelmente, um estudo mais amplo, que contemple as diversas realidades espaciais - suportes simbólicos das comunidades que conheceram processos de mudança da sua respectiva tipologia principal-, mostraria que essas reflexões teóricas fazem sentido e são pertinentes quando se trata de intervir em estruturas espaciais urbanas consolidadas. IEURE 


\section{Referências bibliográficas}

Augé, M. (1994). Não-lugares: introdução a uma antropologia da supermodernidade. Campinas: Papirus. Bobbio, N. et al. (2007). Dicionário de política. Brasília: Editora Universidade de Brasília.

Certeau. M. de (2002). A invenção do cotidiano - 1. Artes de fazer. Petrópolis : Vozes.

Choay, F. (1965). L'urbanisme. Utopies et realités. Paris: Le Seuil.

Dewitte, J. (1999). L'unité dans la multiplicité. Revue du Mauss. 14: 78-94.

Duvignaud, J. (1977). Lieux et non lieux. Paris: Éditions Galilée.

Lefevbre, H. (1986). La production de l'espace. Paris: Anthropos.

Larochelle, P. \& Iamandi, C. (1999). Continuity and change in anthropic environments: toward a control based on the knowledge of historical transformation processes. Em S. Zancheti (ed.). Conservation and urban sustainable development: a theoretical framework. Recife: Editora Universitária da UFPE.

Leitão, L. (2007). Sobre o espaço edificado e suas marcas identitárias. Revista Veredas. 13: 79-83.

Ledrut, R. (1979). Sociologie urbaine. Paris: Presses Universitaires de France.

Lacerda, N. (1993) La production sociale des intérêts fonciers et immobiliers - le cas de Recife (Brésil). Tese de doutorado em Géographie, Aménagement et Urbanisme. Université Sorbonne Nouvelle, Paris. 296 pp.

Ostrowetsky, S. (1983). L'imaginaire bâtisseur. Les villes nouvelles françaises. Paris: Librairie des Méridiens.

Remy, J. \& Voye, L. (1992). La ville: vers une nouvelle definition? Paris: L'Harmattan.

Secchi, B. (1998). Un progetto per l'urbanistica. Torino: Einaidi.

Weber, M. (1999) Economia e sociedade: fundamentos da sociologia compreensiva. Brasília: Editora

Universidade de Brasília. 